\title{
Prenatal Fetal Life in the Mother
}

\section{Kazuo Maeda*}

Department of Obstetrics and Gynecology (Emeritus), Tottori University Medical School, Yonago, Japan

\begin{abstract}
Aims: Fetal life and environment should be known in the management of the mother, fetus and newborn.

Details; Fetal living and environment are very different from postnatal state, and a fetus lives and grows depending the transfer of oxygen and nourishing materials through the placenta, which attached the uterus, and supported by the umbilical cord circulation. Environment temperature is stabilized by maternal body temperature, humidity is nearly $100 \%$, because the fetus is immersed in amniotic fluid. Fetal circulation differs from postnatal one due to placental circulation and no air respiration. Since the fetus grows floating in amniotic fluid, the fetus lives in the condition of no gravity, which supports fetal movements, and the blood circulation in the long umbilical cord vessels. The acoustical and visual fetal capacities were confirmed by sound and light stimulation, and fetal response with fetal movement and FHR acceleration.
\end{abstract}

Conclusion: The fetal life and growth are useful in the fetal monitoring and postnatal preterm infant incubation.

Keywords: Fetus Mother; Amniotic fluid; Fetal circulation; Fetal nourishment; No gravity; Temperature; Humidity; Preterm incubation

\section{Introduction}

We must know intrauterine fetal life not only for the fetal monitoring, but also for the care of mother and fetus as an integrated life, and particularly for the incubation of preterm infant, where the reproduction of intrauterine environment is desired. Assisted reproductive technology is artificial reproduction of fertilization, where the knowledge on natural fertilization is mandatory. Also there is unique fetal circulation associated with the placental fetal circulation, The knowledge is important in the prenatal echocardiography. Various congenital anomalies may be found in the ultrasound fetal image study, of which knowledge is mandatory in fetal management. Other fetal disorders will be diagnosed on the base of fetal life in the mother. Fetal acoustic and visual functions will be studied as a part of fetal monitoring, namely they are important in fetal and neonatal life.

\section{Detailed fetal life}

Fertilization to Implantation: All ovums are prepared in female neonatal ovary at birth, and grows one by one in the puberty. Usually an ovarian follicle contains an ovum, to grow under the effect of follicle stimulating hormone, which promote the development of follicle and blood flow in ovary at the same time as the ovum, and the endometrium increases its thickness by the effect of estrogen to form the suitable bed for the implantation of fertilized ovum. Maternal hypophysis excretes massive luteinizing hormone $(\mathrm{LH})$ by the triggering of increased estrogen in the blood, and fully developed follicle ruptures to release the ovum. After the ovulation the ovum is caught by the fimbria of Fallopian tube and sent to the tube, where the ovum meets sperm and is fertilized [1,2].

The ovum is fertilized outside of mother in the in-vitro fertilization (IVF) or intracytoplasmic sperm injection (ICSI), but the embryo is transferred into maternal uterine cavity, namely, the embryo and fetus develop in the mother's uterus until the birth. The fertilized ovum is divided into 2-cells, 4-cells, 8 cells to form a morula, where one of morula cells were sampled and examined for prenatal diagnosis, namely, the morula cell has no personality before forming blastula, which is a sphere including early stage embryo and escapes zona pellucida (ZP) to contact thick endometrium of rich blood flow. The trophoblasts cover the placenta villi to keep the nutritional and gas-exchange function of placenta.
A yolk sac, which is a hematopoietic organ, is located outside embryonic membrane, connecting the embryo with a stalk including blood circulation to the embryo.

Each tissue and organ starts to develop and grow, particularly the central nervous system forms a spinal cord and primary brain at its upper pole, then enclosed in the cranium and vertebral column [1,2].

\section{The role of placental villi}

The embryo develops prior to 10 weeks of pregnancy without bone, and the fetus develops bone in 10 or more weeks. Extracorporeal circulation is established in placental villi through the umbilical cord vessel. The villi are composed of fetal capillary covered by fetal tissue and chorionic plate, and immersed in maternal arterial blood in the placenta, which is supplied from maternal uterine artery. Fetal nutritional material and oxygen penetrate the villus wall flowing into fetal capillary blood and contributes to fetal growth and oxygenation. Placental function is supported by the villi composed of chorionic membrane and fetal capillaries, which are floated in maternal arterial blood.

The placental villi prepare two transfer functions from maternal to fetal blood [3-5]. Fetal growth is supported by the active transfer of villi, thus the nutritive material concentration is higher in fetal blood than maternal blood, e.g. fetal blood glucose concentration is higher than that of maternal one. Fetal growth is restricted if the villous active transfer function is damaged, e.g. in the placental infarction.

Placental gas transfer is supported by simple gradient between the mother and fetus, namely, oxygen is transferred from maternal high $\mathrm{PaO}_{2}$ blood to low $\mathrm{PaO}_{2}$ blood of the fetus, while $\mathrm{PCO}_{2}$ is higher in fetal blood than maternal one and transferred from fetal to maternal blood.

*Corresponding author: Kazuo Maeda, Department of Obstetrics and Gynecology (Emeritus), Tottori University Medical School, Yonago, 3-125, Nadamachi, Yonago, Tottoriken, 683-0835, Japan, Tel: 81-859-22-6856; E-mail: maedak@mocha.ocn.ne.jp

Received September 16, 2014; Accepted December 04, 2014; Published December 08, 2014

Citation: Maeda K (2015) Prenatal Fetal Life in the Mother. J Health Med Informat 6: 177. doi:10.4172/2157-7420.1000177

Copyright: (c) 2015 Maeda K. This is an open-access article distributed under the terms of the Creative Commons Attribution License, which permits unrestricted use, distribution, and reproduction in any medium, provided the original author and source are credited. 


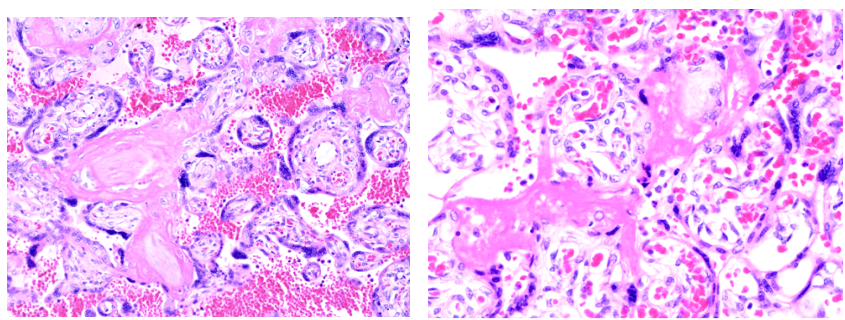

Figure 1: Microscopic view of fibtin deposit in the intervillous space og FGR placenta (Courtesy of Dr. Utsu, Seirei hospital).

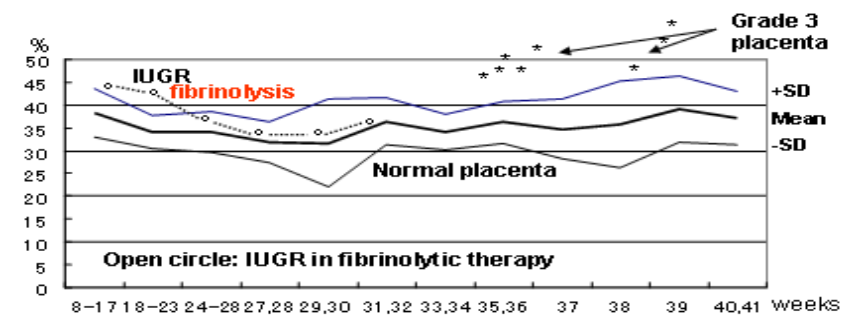

Figure 2: The change in placental GLHW'(ultrasonic tissue characterization) in the IUGR(FGR) case during Heparin administration, comparing to normal placenta GLHW.
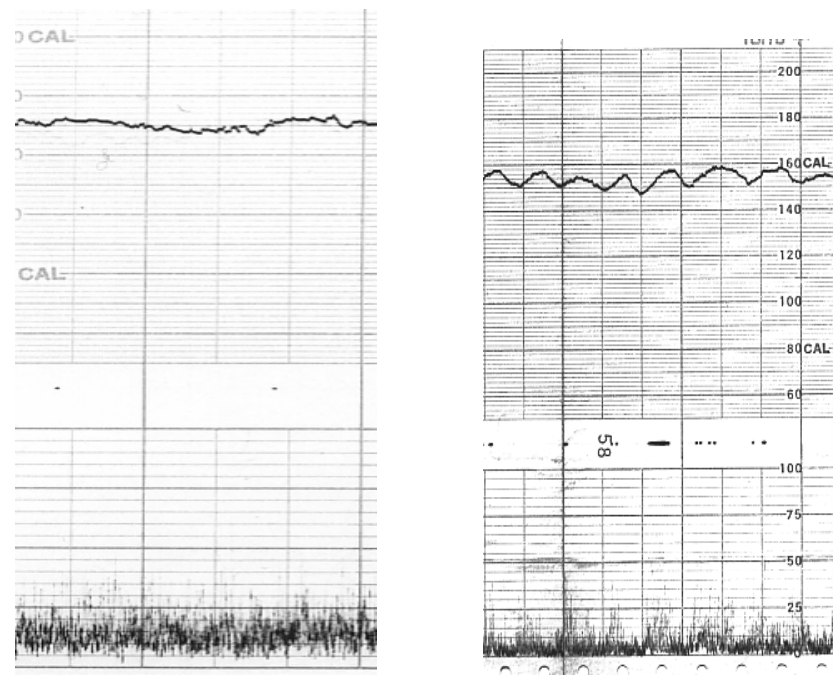

Figure 3: Continuous fetal respiratory movements. B. Periodic change of fetal respiratory movements.

The gas transfer would be preserved even after the damage of active transfer, and fetal hypoxia, caused by placental dysfunction, would appear by the damage of placental simple transfer function in the fetal growth restriction (FGR), namely, fetal hypoxia should be predicted in the FGR.

\section{Intervillous space fibrin deposit and fetal growth restriction (FGR)}

Fibrin is deposited in intervillous space to impede maternal blood flow circulation, to interfere with fetal nutrition, and to develop FGR.

The fibrin mass fills intervillous space of placenta (Figure 1) causing the reduction of maternal blood flow to supply nutritional materials and later reducing oxygen supply to the fetus, namely it restricts fetal growth then later produce fetal hypoxia, causing NRFS (former fetal distress) and later fetal neurological sequels or fetal demise.

An FGR fetus showed white placenta in B-mode and large gray level histogram width (GLHW) value in a case of FGR in our experience, where the mother had a fetal demise in previous pregnancy, placental fibrin deposit was diagnosed by the B-mode and GLHW, which were a tissue characterization, and 5,000 IU heparin was administered every day. The GLHW value decreased and estimated fetal weight increased after the fibrinolytic therapy, and then normal neonate was obtained in our study (Figure 2) [6]. An FGR may be successfully treated with the fibrinolysis, when ultrasound image and GLHW suggest placental fibrin deposit.

\section{Fetal floating in the amniotic fluid by the loss of gravity}

The fetal blood flows through the placenta via umbilical cord vessels, including two umbilical arteries and one umbilical vein, which supplies placenta fetal venous blood after the oxygenation of fetus through two umbilical arteries, and flow back refreshed oxygenated arterial blood, which is rich of nutritional material due to placental function, to the fetus through single umbilical vein. Since the fetus and umbilical cord are floating in the amniotic fluid achieving no gravity as to stay in the space station [7], the fetus freely moves in the fluid, and the blood in umbilical vessels easily circulates through long umbilical cord, even fetal blood pressure is supposed to be as low as $50 \mathrm{mmHg}$ [2]. Even a fetus of congenital muscle atrophy was able to move in the uterine amniotic fluid during pregnancy in actocardiographic study, while the neonate could not move after birth in the earth gravity in our experience.

\section{Nourishment and Breathing}

A fetus does not eat but repeatedly drink amniotic fluid. Anencephalic fetus does not drink but discharge urine, thus amniotic fluid increased to form hydramnios. Renal agenesis fetus does not produce urine, thus develop oligohydramnios,

A fetus does not breath air but repeats continuous respiratory movements, of which frequency is $1 \mathrm{~Hz}$, Also periodically changing repeated respiratory or mouthing movements evokes physiologic pseudo sinusoidal heart rate of normal outcome in the actocardiogram and differentiates from true sinusoidal FHR (Figures 3 and 4) [8].

Fetal hiccupping movements with 2-3 S intervals lasts several 10 min without FHR acceleration, which differentiate true non-reactive FHR in the actocardiogram (Figure 5). Fetal yawn and extruding tongue are observed by 3 and $4 \mathrm{D}$ ultrasound [9].

\section{Fetal Circulation}

Fetal circulation is unique due to the presence of placental circulation and no air respiration which causes high resistance to pulmonary circulation, i.e. right ventricle output bypasses pulmonary arterial circulation flowing through ductus arteriosus to the aorta, then fetal body and umbilical arteries.

Fetal electrocardiography was useful to diagnose fetal life objectively, but the role was switched to ultrasonic Doppler fetal heart detector [10]. The fetal phonocardiography, the recording of fetal heart tones using abdominal microphone, detected systolic murmur in normal pregnancy, which was not detected in the neonate after birth, and supposed to be the sound derived from ductus arteriosus blood flow (Figure 6) [11]. 

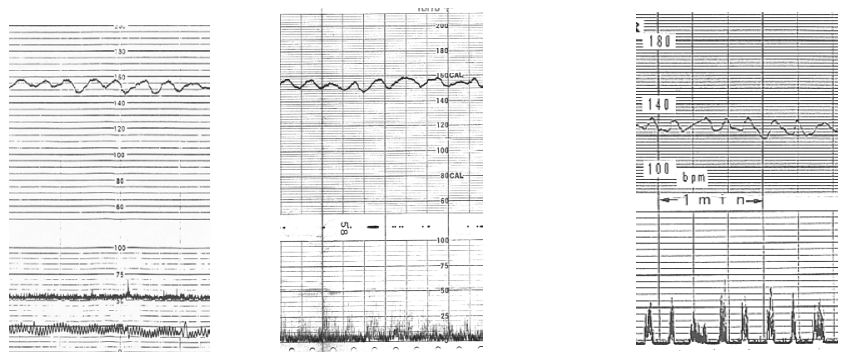

Figure 4: True sinusoidal FHR without fetal movement. B. Physiologic pseudo sinusoidal FHR provoked by periodic change of fetal respiratory movements. C. Physiologic pseudo sinusoidal FHR provoked by fetal mouthing movements.

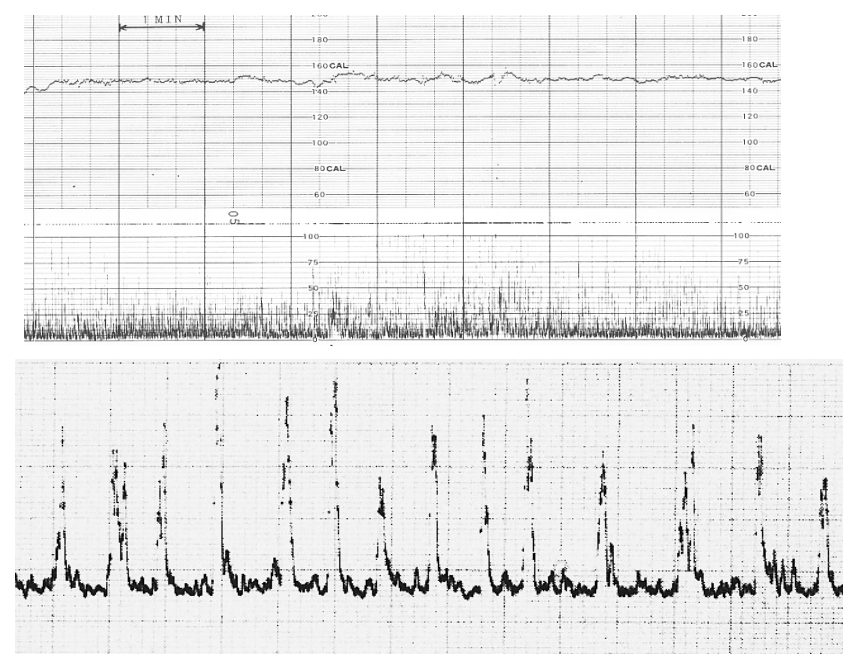

Chart speed: $1 \mathrm{~cm} / 2 \mathrm{sec}$

Figure 5: Fetal hiccupping movements. A. Common chart speed $(3 \mathrm{~cm} / \mathrm{min})$. B. Rapid bhart speed $(1 \mathrm{~cm} / 2 \mathrm{sec})$ shoeing regular $2 \mathrm{~S}$ hiccupping interval.

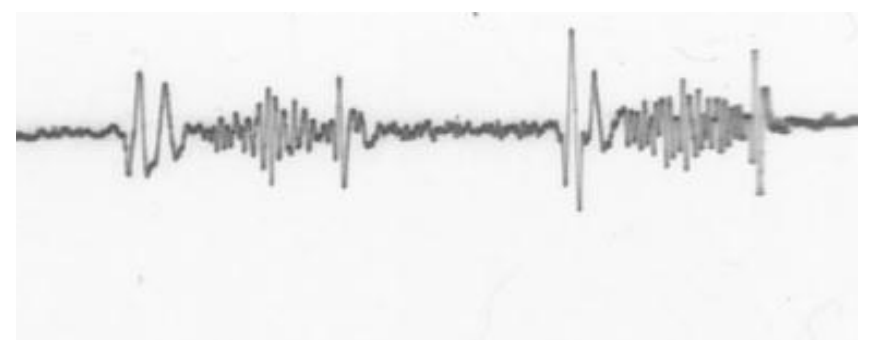

Figure 6: Fetal phonocardiography. The systolic murmur (arrows) was recorded in $17 \%$ of normal pregnancy fetuses. The murmur may be the ductus arterosus blood flow.

\section{Hearing and looking function of the fetus in-utero}

Fetal ability to hear the sound was tested by fetal response to the stimulation with pure $1,000 \mathrm{~Hz}$ sound produced with a signal generator, where its intensity was measured by an audiometer. The fetus was stimulated with $80 \mathrm{~dB}$ sound in 28 weeks of pregnancy, where fetal response to the sound stimulation was fetal movements followed by FHR acceleration recorded with the actocardiogram. In the repeated sound stimulation in 40 weeks of pregnancy, the fetus responded the sound of $60 \mathrm{~dB}$ intensity. The results will show increased fetal hearing capacity for $+20 \mathrm{~dB}$ in late pregnancy.

The fetus was stimulated by the light with a photographic flashlight of GN 20 intensity. Thirty \% of fetuses firstly responded to the light stimulation with fetal movement and FHR acceleration with actocardiogram in 23 weeks of pregnancy. The positive response gradually increased and it was $70 \%$ in 40 weeks of pregnancy.

Therefore, it was clear that a prenatal fetus is able to hear the sound and to See the light with increasing sensitivity in the late stage of pregnancy [12].

\section{Temperature and humidity of fetal environment}

Intrauterine temperature will be almost stabilized at around 36 ${ }^{\circ} \mathrm{C}$ in healthy mother. The fetal heart rate increased to be tachycardia, when the mother is suffered by febrile disease.

Since the fetus is immersed in amniotic fluid, environmental humidity will be $100 \%$. Therefore the preterm infant incubator temperature should be higher than room temperature, and the air in the incubator should be kept in high humidity.

\section{Discussion and Conclusion}

A fetus lives in a narrow but comfortable environment without eating foods and breath air, while the gas exchange and nutrition were supported by the placenta, which was a fetal organ, and discarded after the air respiration and milk drinking in the neonate.

Fetal circulation was also unique with the ductus arteriosus, which bypass pulmonary circulation, and the presence of umbilical vessels to enable placental circulation. No gravity is a dominant condition of fetal environment if compared to the neonate, who faces the earth gravity after the birth, and it will take for a year to overcome the earth gravity and walk in the infant life. The constant temperature and high humidity are also characteristic in the fetal life in utero, which drop significantly after the birth and should be highly controlled in the preterm neonatal incubator.

\section{References}

1. Cuningham I, Leveno Kj, Bloom SL (2010) Williams Obstetrics. (24 ${ }^{\text {th }}$ edition), McGraw-Hill Education, New York.

2. Kurjak A, Franc AC (2006) Textbook of Perinatal Medicine ( $2^{\text {nd }}$ edition), Informa UK, London, Tailor \& Francis, New York.

3. Page EW (1965) Physiology and biochemistry of the placenta. In Greenhill Obstetrics, Saunders, Philadelphia.

4. Battaglia FC, Hellegers AE, Meschia G, Barron DH (1962) In vitro investigations of the human chorion as a membrane system. Nature 196: 1061-1063.

5. Seeds AE, Schruefer JJ, Reinhardt JA, Garlid KD (1973) Diffusion mechanisms across human placental tissue. Gynecol Invest 4: 31-37.

6. Maeda K, Utsu M, Kihaile PE (1998) Quantification of sonographic echogenicity with grey-level histogram width: a clinical tissue characterization. Ultrasound Med Biol 24: 225-234.

7. Meigal A (2012) Interplanetary space flight compared with fetal/neonatal motor strategy: Theoretical and practical implications. Pathophysiology 19: 269-276.

8. Ito T, Maeda K, Takahashi H, Nagata N, Nakajima K, et al. (1994) Differentiation between physiologic and pathologic sinusoidal FHR pattern by fetal actocardiogram. J Perinat Med 22: 39-43.

9. Kurjak A, Abo-Yaqoub S, Stanojevic M, Yigiter AB, Vasilj O, et al. (2010) The potential of $4 \mathrm{D}$ sonography in the assessment of fetal neurobehavior-multicentric study in high-risk pregnancies. J Perinat Med 38: 77-82.

10. Maeda K, Nakano H (1968) Experiences with the technique of ultrasonic Doppler method in obstetrics. J Jpn Obstet Gynecol Soc 15: 135-142. 
Citation: Maeda K (2015) Prenatal Fetal Life in the Mother. J Health Med Informat 6: 177. doi:10.4172/2157-7420.1000177

Page 4 of 4

11. Maeda K, Nakano H (2014) Antenatal Phonocardiography of Intrauterine Fetus: Physiological Monitoring of Fetal Heart Sounds. J Health Med Informat in press.
12. Maeda K, Tatsumura M, Utsu M (1999) Analysis of fetal movements by Doppler actocardiogram and fetal B-mode imaging. Clin Perinatol 26: 829-851. 